\title{
ESCOLARIZAÇÃO E PROJETO DE VIDA DE JOVENS DA RESERVA EXTRATIVISTA DO RIO CAJARI
}

\section{SCHOOLING AND YOUTH LIFE PROJECT OF CAJARI RIVER EXTRACTIVE RESERVE}

\author{
NASCIMENTO, Ivany Pinto ${ }^{1}$ \\ MENDES, Débora Mate ${ }^{2}$
}

\begin{abstract}
RESUMO
O presente artigo tem como objetivo abordar os resultados parciais do estudo realizado no ano de 2018 sobre os projetos de vida na relação com os processos de escolarização de jovens estudantes, concluintes do ensino médio das escolas da Reserva Extrativista do Rio Cajari (RESEX-CA), no sul do estado do Amapá, na região Amazônica. Trata-se de um recorte de dados de uma pesquisa qualitativa do tipo descritiva-analítica. O instrumento utilizado foi o questionário semiestruturado, aplicado aos estudantes do terceiro ano do ensino médio, totalizando vinte e três sujeitos. A análise das informações ocorreu na perspectiva da análise temática. Os resultados apontam para três temas: os desafios para acesso ao ensino médio, a permanência no campo e o projeto de vida. Vale destacar que essas três temáticas centralizam os principais sentidos que respondem a compreensão dos projetos de vida dos jovens na relação com seus processos de escolarização, foco do presente estudo.
\end{abstract}

PALAVRAS-ChaVe: juventude do campo - escolarização - projeto de vida.

\begin{abstract}
This article aims to address the partial results of the study conducted in 2018 on life projects in relation to the schooling processes of young students, graduating from high schools of the Cajari River Extractive Reserve (RESEX-CA), in southern Amapá state in the Amazon region. It addresses a selection of data from a descriptive-analytical qualitative research. A semi structured questionnaire was use and applied to $12^{\text {th }}$ grade students, totaling twenty-three subjects. Analysis of the information was conducted under the perspective of thematic analysis. Results point towards three main themes: challenges for access to high school, permanence in rural areas and life project. Those three themes comprehend the main meanings that respond to the understanding of young people's life projects in relation to their schooling processes, which is the focus of the present study.
\end{abstract}

KEYWORDS: rural youth; schooling; life project.

\footnotetext{
${ }^{1}$ Universidade Federal do Pará (UFPA) / Programa de Pós-Graduação em Educação (PPGED). Belém, PA, Brasil. ORCID: https://orcid.org/0000-0002-2455-3676 e-mail: ivany.pinto@gmail.com

2 Universidade Federal do Pará (UFPA). Belém, PA, Brasil. Universidade Federal do Amapá (UNIFAP). ORCID: https://orcid.org/0000-0001-5312-3707 e-mail: bedamate@hotmail.com
} 
DOI: $10.12957 /$ e-mosaicos.2020.44638

\section{INTRODUÇÃO}

O presente artigo teve como foco abordar os resultados parciais do estudo realizado no ano de 2018 sobre os projetos de vida na relação com os processos de escolarização de jovens estudantes, concluintes do ensino médio, da Reserva Extrativista do Rio Cajari (RESEX-CA) situada na Amazônia, no estado do Amapá, região norte do Brasil.

Segundo o Censo Demográfico de $2010^{3}$, os/as jovens residentes no meio rural brasileiro somam um total de 7.807.627, o que corresponde a aproximadamente $5 \%$ do total da população brasileira e o equivalente a $1 / 3$ da população rural brasileira. $A$ preocupação com a sua permanência (ou não) no campo é alvo de debates em diferentes setores da sociedade e vem pautando pesquisas acadêmicas nas diferentes regiões do país.

Segundo o Instituto de Pesquisa Econômica Aplicada (IPEA), as populações rural e urbana no Brasil apresentam uma significativa desigualdade no Índice de Desenvolvimento Humano Municipal (IDHM). Dentre os grupos analisados pelo estudo, intitulado Desenvolvimento humano para além das médias, publicado em 2017, este se destacou como o grupo de maior desigualdade entre os analisados. Quando se observa os dados do estado do Amapá referentes ao IDHM, calculado pelo Ipea no ano de 2015 , vemos que a área urbana tem um índice de 0,746 , considerado alto nos parâmetros do instituto, enquanto a área rural apresentou o índice de 0,595, apontado como baixo.

As desigualdades apontadas são resultadas da dificuldade de acesso às políticas públicas nas comunidades rurais no estado do Amapá, que acarretam inúmeros desafios enfrentados pelos/as jovens para permanecerem no campo e, ainda, construírem alternativas de acesso e permanência na escola, especialmente no ensino médio.

Para além dos dados, é importante inferir que o lugar onde a pesquisa foi realizada tem modos de vida específicos, que se constroem nas relações entre os sujeitos e destes com o território, em uma região que tem atividades agropecuárias, e mais do que isso é também uma área protegida ${ }^{4}$, constituída por florestas, rios, igarapés e lagos. As especificidades desse lugar e as trocas entre esses sujeitos possibilitam a construção de sua singularidade simbólica. Esse processo de trocas e interações é apresentado por Nascimento (2015) da seguinte forma:

A singularidade simbólica da cultura local de cada sociedade é perpassada, por um lado, por uma sinalização que se configura em uma rede de conexões interativas, e por outro lado, cada cultura ao depender de sua dinâmica histórico-social, avança em diferentes níveis por uma codificação em que a mídia participa efetivamente da legitimação deste capital simbólico. (NASCIMENTO, 2015, p. 47).

\footnotetext{
${ }^{3}$ Disponível em: https://sidra.ibge.gov.br/tabela/200. Acesso em: 15 set. 2019.

${ }^{4}$ Diploma Legal de Criação: Dec. no 99.145 de 12 de março de 1990.
} 
DOI: $10.12957 /$ e-mosaicos.2020.44638

Essa singularidade simbólica vivenciada pelos/as jovens amazônidas é perpassada por aspectos culturais específicos e que são repassados de geração em geração. Ao mesmo tempo, essa cultura é atravessada pelas novas tecnologias que, de maneira precária ${ }^{5}$, chegam a essas comunidades em alguns pontos de acesso aos serviços públicos, como exemplo, em escolas e unidades de saúde.

Ao considerar o cenário revelado pelos dados e a singularidade simbólica local, o presente estudo se preocupou com o seguinte questionamento: como os/as jovens da RESEX-CA, concluintes do ensino médio, planejam seus projetos de vida, enlaçados aos processos de escolarização em que estão inseridos? Para responder a esse questionamento, buscamos delimitar quem são esses/as jovens, quais os processos de escolarização em que estão inseridos no ensino médio e quais os seus projetos de vida.

\section{JUVENTUDE DO CAMPO, ESCOLARIZAÇÃO E PROJETO DE VIDA}

Para pensar juventude do campo e seus projetos de vida, enlaçados aos processos de escolarização, é necessário observar como esses conceitos emergem ao longo do tempo e como ocorre o processo de construção de identidade. Nesse sentido, um aspecto que se apresenta como recorrente nas produções de diferentes autores diz respeito à vinculação dos/as jovens com o território. Esse aspecto aparece como constitutivo no sentido de que é nesse lugar que esses sujeitos constroem suas identidades e estes são atravessados pelos modos de vida e pelas relações sociais e de produção, estabelecidas nesse contexto que possibilitam, em diferentes medidas, a vivência e a construção da condição juvenil.

É possível observar essa afirmação nos estudos de Durand e Alves (2015) sobre a busca de escolarização/qualificação de jovens do estado de Santa Catarina, participantes do Programa ProJovem Campo - Saberes da Terra, ao evidenciarem que a construção do ser jovem está ligada a questões regionais e locais dos grupos em que estão inseridos. O estudo de Alves $(2015$, p. 87) sobre a condição juvenil em contexto rural a partir das especificidades de um município rural mineiro revela que: "A questão territorial é um fator significativo na constituição identitária e na condução e elaboração dos projetos de vida dos jovens".

Além da vinculação com o território, outro aspecto chave para entendermos a juventude do campo é a condição Juvenil, visto que os jovens do campo aparecem ora como vítimas, ora como culpados no que tange à continuidade e a reprodução do campo (DURAND; ALVES, 2015), em grande medida desconsiderando as desigualdades impostas a esses sujeitos na vivência da condição juvenil.

\footnotetext{
${ }^{5}$ As comunidades do território da Resex-CA têm poucos pontos de acesso à internet em locais como Escolas e Unidades de Saúde. O sinal é fraco e oscila muito, tornando o acesso difícil. Além disso, a energia elétrica nessas comunidades é proveniente de geradores que são ligados durante poucas horas do dia, somente, nesse período, o sinal fica disponível.
} 
DOI: $10.12957 /$ e-mosaicos.2020.44638

Nessa direção, compartilhamos a reflexão, proposta por Leão e Antunes-Rocha (2015), ao pensarem os sujeitos em seu tempo histórico a partir da compreensão de Condição Juvenil, no sentido de reconhecer que são atribuídos valores à juventude, considerando não somente a questão geracional, como também, que existem condicionantes sociais impostas.

Ao partir desse entendimento, podemos constatar que é impossível conceber a existência de uma juventude universal ou um tipo ideal de jovem, mas é fundamental considerar as múltiplas juventudes e seus contextos de vida. Essas juventudes têm para além das dimensões de classe, gênero e pertencimento étnico-racial especificidades simbólicas, culturais e possibilidades de viver (ou não) a condição juvenil, conforme abordam Leão e Antunes Rocha (2015, p.19): "dimensões simbólicas e culturais, como também [...] situações materiais que definem limites e possibilidades de viver a condição juvenil".

Nesse sentido, nossa reflexão assume como referência a Juventude do campo da Reserva Extrativista do Rio Cajari, sujeitos que para além da faixa etária, pertencem a grupos sociais que possuem modos de vida específicos e que se constituem a partir de dimensões múltiplas que vão desde elementos técnicos do seu processo de trabalho até questões simbólicas e ritos próprios da sua cultura.

Diante do exposto, torna-se fundamental pensar os/as jovens do campo como sujeitos que têm a capacidade de intervir na realidade e transformá-la. Ou seja, é necessário romper com a ideia de que os/jovens não pensam por si e incorporam de maneira passiva modelos culturais preestabelecidos e difundidos pelos meios de comunicação, para vislumbrá-los como sujeitos que dialogam, se organizam e constroem sua trajetória pessoal e coletiva (LEÃO; ANTUNES-ROCHA, 2015).

A partir dessa compreensão, torna-se necessário pensar os processos de escolarização, a inserção dos/as jovens do campo no sistema formal de ensino. Desse modo, vislumbramos como um caminho a busca por compreender os desafios enfrentados pelos/as jovens na escola e a relação com seus projetos de vida.

$\mathrm{Na}$ atualidade, há uma certa naturalização dos processos de escolarização, dos/as jovens enquanto alunos e dos papéis atribuídos a eles/as. Porém, como afirma Penatieri: "[...] a escola nem sempre existiu, trata-se de uma instituição situada no(s) tempo(s) e espaço(s), por isso a importância do olhar histórico" (PENATIERI, 2012, p. 3). Se considerarmos especificamente o ensino médio, a expansão e o acesso, ainda, são conquistas recentes e até mesmo um desafio para os/as jovens do campo.

Muito embora o ensino médio tenha passado por um processo recente de expansão ${ }^{6}$, para Penatieri (2012), esse momento da escolarização se constitui como

${ }^{6}$ BRASIL. Lei no 12.061, de 27 de outubro de 2009. Altera o inciso II do art. 40 e o inciso VI do art. 10 da Lei no 9.394, de 20 de dezembro de 1996, para assegurar o acesso de todos os interessados ao ensino médio público. Brasília, DF, Presidência da República. Disponível em: http://www.planalto.gov.br/ccivil_03/_Ato2007-2010/2009/Lei/L12061.htm. Acesso em: 15 set. 2019. 
DOI: $10.12957 /$ e-mosaicos.2020.44638

um espaço significativo de sentido, visto que no seu bojo se evidenciam desigualdades e oportunidades distintas nos diferentes âmbitos da sociedade brasileira as quais produzem marcas na juventude. Ao mesmo tempo pode ser considerado um espaço de construção e luta por direitos desses/as sujeitos.

Em geral, a noção de escolarização está associada ao conceito de educação, porém, a forma como a escola está organizada atualmente é um processo de construção recente e sua implantação não ocorreu de maneira uniforme nos diferentes lugares e regiões (CAMPOS; RODRIGUES; VITKOWSKI, 2012).

Desse modo, destacamos que os processos de escolarização, no ensino médio das comunidades do campo no Amapá, ocorrem de três formas distintas. A primeira é a modalidade chamada regular que é ofertada pela Secretaria de Estado de Educação (SEED) em escolas de distritos e comunidades mais populosas; a segunda é o Sistema de Organização Modular de Ensino (SOME), também ofertada pela SEED, porém, em escolas de comunidades mais distantes, de difícil acesso e mais dispersas territorialmente. A terceira é ofertada pelas Escolas Famílias Agroextrativistas e Agrícolas que promovem Educação do Campo por meio da Pedagogia da Alternância e são geridas por associações ${ }^{7}$ próprias que acessam recursos públicos de convênios com o Governo do Estado, além de outras fontes de financiamento.

As unidades escolares, onde a presente pesquisa foi realizada, desenvolvem suas atividades por meio do Sistema de Organização Modular de Ensino (SOME), conhecido popularmente na região como "módulo", modalidade em que o professor de cada disciplina permanece na escola por um período determinado para ministrar todas as aulas da sua disciplina em bloco e retorna para a cidade.

A Lei no 0949, de 23 de dezembro de 2005, publicada no Diário Oficial do Estado no 3668 , de 23.12.2005, apresenta em seu artigo 59 a possibilidade de implantação do Sistema Modular de Ensino:

Art. 59 - Nas localidades do Estado em que não seja possível estruturar e colocar em funcionamento o ensino fundamental e médio regular será implantado, em caráter excepcional, o Sistema Modular de Ensino, desde que observadas as seguintes condições:

I - comprovação da existência de, pelo menos, 20 (vinte) alunos por série;

II - disponibilidade de alojamento ou local adequado para moradia dos professores;

III - existência de infra-estrutura (sic) física compatível com o ambiente escolar. (BRASIL, 2005, s/p).

\footnotetext{
${ }^{7}$ As Escolas Famílias têm associações mantenedoras próprias que são responsáveis pela gestão das Escolas.
} 
DOI: $10.12957 /$ e-mosaicos.2020.44638

É nesse contexto que situamos a experiência escolar desses jovens e buscamos compreender a forma como se relacionam com a escola, as suas demandas e necessidades próprias. Dessa maneira, compreender seus projetos de vida passa por vislumbrar os desafios e os fatores que influenciam na decisão de permanecer (ou não) no campo, tomando como referência a ideia de projeto de vida como um plano de ação que tem um lapso temporal mais ou menos longo. Leão, Dayrell e Batista dos Reis (2001, p. 1071) apresentam essa definição da seguinte forma: "A ideia de projeto de vida remete a um plano de ação que um indivíduo se propõe a realizar em relação a alguma esfera de sua vida (profissional, escolar, afetivo etc.) em um arco temporal mais ou menos largo".

Cabe destacar que esse processo de elaboração ocorre nas trocas entre sujeitos e destes com a sociedade, esse entendimento é apresentado por Nascimento da seguinte forma: "A ideia de que o Projeto de Vida se delineia na relação do sujeito com o mundo nos remete à constituição do sujeito com a sociedade. As histórias de cada um certamente não seriam protagonizadas sem a presença do outro" (NASCIMENTO, 2013, p. 88).

O contexto, onde as relações se concretizam, seja no que diz respeito à situação material, cultural ou simbólica, está intrinsecamente articulado às elaborações de projeto de vida. Para Leão, Dayrell e Batista dos Reis (2001, p. 1071): "[...] tais elaborações dependem sempre de um campo de possibilidades dado pelo contexto socioeconômico e cultural no qual cada jovem se encontra inserido e que circunscreve suas experiências".

Desse modo, a escola - do ensino médio - é entendida, neste estudo, como espaço de trocas e partilhas onde os/as jovens encontram uns/mas nos/as outros/as a possibilidade de presença do/a outro/a que também se constrói e possui expectativas e desejos. Para Nascimento (2013, p. 88): "A presença do outro reenvia a ideia de partilha necessária tanto às particularidades da vida de cada sujeito como para a vida na relação com o outro".

O convívio diário e os processos de aprendizagens, especialmente nesse momento da vida escolar em que os/as jovens projetam suas expectativas e desejos de futuro, possibilitam esses vínculos relacionais que se constroem, tanto objetiva como subjetivamente, individual e coletivamente, afirma Nascimento (2013).

Esse espaço de convivência diária permite intercambiar visões de mundo, dificuldades e aspirações, situações concretas do cotidiano, bem como, aspectos simbólicos, culturais que são importantes na constituição dos sujeitos, conforme salienta Nascimento (2013, p. 88): "O Projeto de Vida emerge nessa trama complexa de relações, de construção de saberes sobre si e sobre o mundo na medida em que significados são partilhados no cotidiano". Considerando a importância desses processos de troca e construção de si e do outro, o presente estudo se desenvolveu com jovens matriculados no terceiro ano do Ensino Médio. 
DOI: $10.12957 / \mathrm{e}-\mathrm{mosaicos} .2020 .44638$

\section{Percurso metodológico}

A pesquisa que ora apresentamos os resultados parciais é de cunho qualitativo, do tipo descritiva-analítica na perspectiva apontada por Gil (2008), por considerar as características da juventude da RESEX-CA e estabelecer relações entre as variáveis relacionadas aos projetos de vida desses sujeitos, enlaçados com os processos de escolarização. O autor afirma que "[...] são inúmeros os estudos que podem ser classificados sob este título e uma de suas características mais significativas está na utilização de técnicas padronizadas de coleta de dados" (GIL, 2008, p. 28). O instrumento utilizado na coleta de dados foi um questionário semiestruturado com questões fechadas que trataram do perfil socioeconômico dos sujeitos envolvidos, bem como, questões abertas que buscaram investigar os desafios enfrentados pelos jovens no Ensino Médio, os fatores de permanência e saída do campo, além dos seus projetos de vida.

O contexto, onde desenvolvemos a pesquisa foi a Reserva Extrativista do Rio Cajari, que em seu território tem duas escolas que ofertam ensino médio por meio do SOME. A escolha das escolas teve como critério a oferta dessa modalidade de ensino no território que compreende a RESEX-CA. Conforme mapa a seguir:

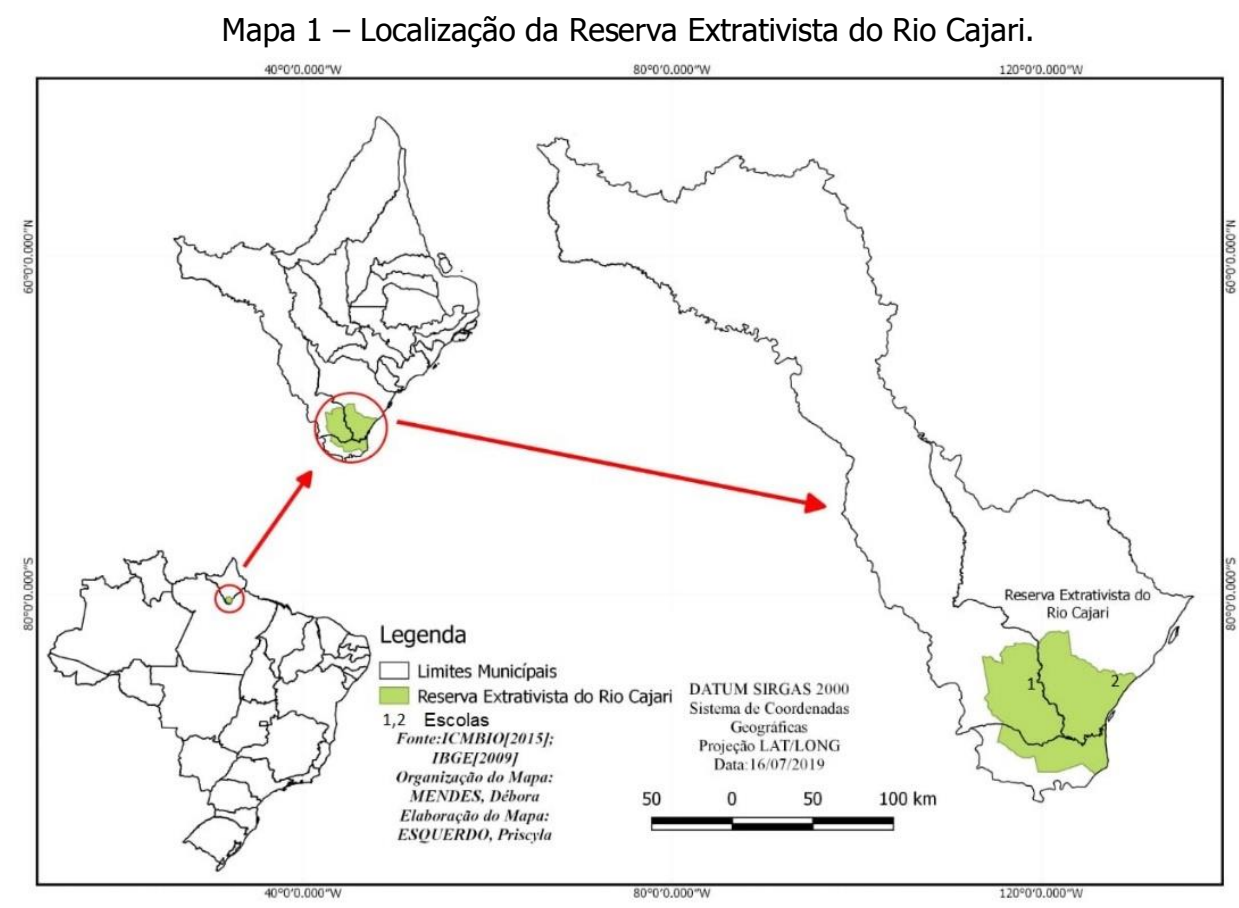

Fonte: elaborado pelos autores

A primeira é a Escola Estadual Água Branca do Cajari (1) com, em média, 100 alunos matriculados, segundo informações da SEED. Está localizada no Município de Laranjal do Jari, região do Alto Cajari, às margens da BR 156 que liga o município a capital, Macapá. A escola atende alunos das comunidades: Água Branca do Cajari, 
DOI: $10.12957 /$ e-mosaicos.2020.44638

Açaizal, Martins, Santarém do Cajari, Itaboca, Boca do Braço, São Pedro, Dona Maria e Poção.

A segunda, Escola Estadual Osmundo Valente Barreto (2) tem em média 120 alunos matriculados e está localizada no Rio Amazonas, próximo a foz do Rio Ajuruxi, na região do Baixo Cajari, município de Mazagão. A escola atende alunos dos rios Ajuruxi, Ariramba, Mulato, Capitão, Chato, Carneiro (todos afluentes do Rio Amazonas pela margem esquerda) e alunos do Rio Arirambinha (afluente do Rio Ariramba). Além de alunos do Rio Curuçá, no Projeto de Assentamento Maracá.

Os jovens do terceiro ano do ensino médio das escolas Água Branca do Cajari e Osmundo Barreto Valente que foram considerados na pesquisa somam um total de 23, ou seja, todos/as os/as jovens terceiranistas que estavam presentes nas atividades escolares na data em que a pesquisa foi realizada foram convidados e se dispuseram a participar. Cabe informar que para preservar suas identidades foram utilizados nomes fictícios nas citações de suas falas. Entre esses sujeitos, 14 são do sexo masculino e nove do sexo feminino, com idade entre 16 e 21 anos, provenientes de 13 comunidades da RESEX-CA.

\section{Projetos de vida dos/AS Jovens da RESEX-CA}

A análise foi realizada por meio do agrupamento das informações dos entrevistados, na perspectiva da análise temática, conforme Braun e Clarke (2006). Desse modo, os temas que emergiram a partir do agrupamento pelas unidades de sentido foram: a) os desafios enfrentados pelos/as jovens para acesso ao ensino médio; b) a permanência no campo; c) os projetos de vida. Vale destacar que essas três temáticas centralizam os principais sentidos que respondem a compreensão dos projetos de vida dos jovens na relação com seus processos de escolarização, foco do presente estudo. A seguir apresentaremos a discussão em torno dos temas gerados e seus respectivos sentidos, para tanto, traremos as falas dos/as jovens para exibir seus pensamentos sobre eles.

A - Desafios enfrentados pelos jovens para acesso e permanência no ensino médio: os sentidos que agrupam essa temática estão relacionados principalmente aos problemas no transporte escolar, ou seja, a precariedade de veículos que quebram com frequência, impedindo que os estudantes cheguem à escola. Podemos observar na seguinte fala: "[...] no meu caso o maior desafio que eu enfrento é a falta de transporte que nem sempre estão disponíveis para nos transportar para a escola, é isso que faz com que fiquemos sem estudar" (jovem Pedro). Um outro sentido encontrado foi a inexistência de veículos desde a sua comunidade, fazendo com que tenham que viver em casas de familiares ou amigos; outros, ainda, dependem de mais de um tipo de transporte - terrestre e fluvial - demandando maior esforço para chegar até a escola. 
DOI: $10.12957 /$ e-mosaicos.2020.44638

Algumas falas dos sujeitos ilustram essa dificuldade, como exemplo, a desse jovem: "[...] os desafios é o transporte, geralmente eu tenho que pegar dois transportes, o barco e o carro para eu vir pra escola e além disso a minha comunidade é um pouco longe" (jovem Danilo). Outro jovem afirma: "[...] venho para essa escola em um transporte fluvial e é muito difícil andar a noite no rio principalmente por que as vezes chove" (jovem Maria).

A dificuldade de deslocamento, enfrentada pelos jovens da RESEX-CA, impõe uma sobrecarga de tempo e esforço que influenciam diretamente no seu desempenho escolar e nas demais atividades desenvolvidas por esses sujeitos fora do ambiente escolar. Essa precarização no acesso à escola é relatada por jovens de outras regiões do país, como exemplo, no estudo realizado por Alves (2015) em um município rural mineiro. Para a autora (2015, p. 91): "Esse ritmo pode ser um comprometedor do desempenho escolar e até um catalizador dos fortes índices de infrequência, evasão repetência e pouco aproveitamento dos estudos".

Outros desafios que estão interligados e foram agrupados nessa temática são: a distância que percorrem até a escola e o horário em que as aulas ocorrem. A Escola Estadual Água Branca do Cajari tem ensino médio noturno, gerando dificuldade para os alunos em relação ao retorno para suas casas, especialmente para aqueles que dependem de transporte fluvial, conforme mencionado anteriormente. Já a Escola Osmundo Valente Barreto oferta o ensino médio matutino e os alunos que residem em comunidades mais distantes precisam sair de casa por volta de 4 horas da manhã. Um estudante afirma que os desafios enfrentados por ele para estudar são: "[...] o transporte, a distância, ter que acordar cedo 4 horas e voltar $1 \mathrm{~h} 30$ da tarde" (jovem Joana).

A qualidade da educação, associada à problemática da falta de professores em algumas disciplinas e o curto espaço de tempo que esses professores permanecem na escola também foram sentidos agrupados na temática relativa aos desafios para estudar, conforme falas dos estudantes: "[...] os desafios é porque os professores vêm muito rápido e, às vezes, a gente não aprende direito, é isso" (jovem Fernando). Outro jovem afirma que sua dificuldade: "[...] é ter que vir para escola 4 h30 da madrugada e não ter conhecimento melhor porque o ensino modular é passageiro" (jovem Cristina). 
DOI: $10.12957 / \mathrm{e}-\mathrm{mosaicos} .2020 .44638$

Tabela 1 - Desafios para estudar.

\section{Desafios para estudar}

\begin{tabular}{l|l}
\hline Transporte & 11 \\
\hline Horário das aulas & 8 \\
\hline Distância da escola & 7 \\
\hline $\begin{array}{l}\text { Falta de professores/Tempo do } \\
\text { "módulo" }\end{array}$ & 6 \\
\hline
\end{tabular}

Fonte: protocolo da pesquisa.

Os principais desafios, vivenciados pelos/as Jovens da RESEX-CA, estão relacionados ao acesso e à permanência na escola, sendo que a dureza e a dificuldade, enfrentadas para se manter no ensino médio é sentida na pele, no sono e no cansaço. Além dos fatores, como: o transporte e a distância percorrida para chegar à escola, também aparece a preocupação com a qualidade da educação.

Os desafios enfrentados pelos jovens são objetos de estudo de vários autores, como exemplo, Marinho (2016) quando observa que, em diferentes medidas, os jovens são afetados por desafios sociais, culturais, produtivos e tecnológicos, estes que dificultam e até podem inviabilizar a sua permanência no campo em algumas circunstâncias.

Podemos observar no estudo de Galindo (2015, p. 107) que os desafios para acessar e permanecer na escola emergem como bandeira de luta nas ações coletivas da juventude visto que essa é uma pauta que não é exclusiva de uma região, mas impacta diferentes territórios do campo brasileiro, conforme afirma a autora: "As adversidades relacionadas ao acesso e permanência na escola permeiam memórias e relatos, ponto de onde emerge uma importante bandeira de luta que orienta a ação coletiva das juventudes organizadas".

Apesar dos desafios apresentados esses sujeitos buscam de todas as maneiras enfrentar os obstáculos, pois há uma crença na escola como via de acesso para uma vida melhor. É possível observar nas falas dos jovens e também nos estudos de autores, como Alves (2015, p. 91-92) que afirma: "Apesar das dificuldades enfrentadas para acessar e permanecer na escola, esses jovens acreditavam nos estudos e evidenciavam uma forte crença na escola como caminho para uma vida melhor".

B - A permanência no campo também emergiu com destaque. Os sentidos agrupados nesse tema estão circunscritos nos fatores que motivam os/as jovens a viverem e construírem seus projetos de vida nesses territórios. Para os/as sujeitos da pesquisa, fatores como a família são importantes para a decisão de permanecer no 
DOI: $10.12957 / \mathrm{e}-\mathrm{mosaicos} .2020 .44638$

campo, conforme a fala de um dos jovens: "[...] minha família é o principal fator que me faz permanecer no campo, mas isso não quer dizer que eu não goste do campo, muito pelo contrário, eu amo viver no campo, isso me faz bem, me traz liberdade para viver" (jovem Pedro). Outro fator recorrente foi o acesso à manutenção cotidiana por meio da produção de alimentos e extrativismo. Nas falas dos sujeitos: "[...] a gente que mora no campo passa fome se quiser porque aqui tem vários meios para nós adquirir alimentos para o nosso dia a dia, caça, peixe, farinha" (jovem Mariana). Outra fala que corrobora nesse aspecto diz o seguinte: "[...] para permanecer no campo você tem a facilidade de conseguir suas coisas diárias, na cidade você trabalha ou você não come" (jovem Marcelo).

Para os/as jovens, estar junto da família é decisivo ao pensar seus projetos de vida, além dos vínculos comunitários e o sentimento de pertencimento que nutrem pelas suas localidades. Porém, contraditoriamente, vislumbram na cidade aspectos que proporcionariam a desejada melhoria nas condições de vida para si e, também, para sua família, afirma Marinho (2016):

Os jovens do campo em sua maioria vivem um constante antagonismo, divididos entre a possibilidade de trilharem projetos mais individualizados na cidade, expresso na vontade de "melhorar a qualidade de vida sua e da família", de "ser alguém na vida" e a vontade de continuar residindo no local de origem, principalmente pela relação com a família e o sentimento de pertencimento com a localidade, já que sua família é o espaço privilegiado de sociabilidade. (MARINHO, 2016, p. 60).

Já o principal fator de saída do campo foi a continuidade dos estudos. A seguinte frase foi repetida pelos jovens: "[...] um dos fatores que contribui para mudar para cidade é fazer uma faculdade" (jovem Ezequiel). Essa fala é associada ao entendimento de que estudar é o caminho para uma vida melhor e/ou possibilitar melhoria de vida aos seus familiares. Desse modo, os sentidos agrupados nessa temática estão relacionados à crença de que é mais fácil conseguir um emprego na cidade, como se percebe na fala deste jovem: "[...] acho que na cidade eu vou ter mais oportunidades, arrumar um emprego e ter estudo melhor, me formar e no futuro poder ajudar as minhas irmãs" (jovem Cristiano). 
DOI: $10.12957 /$ e-mosaicos.2020.44638

Tabela 2 - Fatores de Permanência e saída.

\begin{tabular}{l|l|l|l}
\hline \multicolumn{1}{c|}{ Fatores de Permanência } & \multicolumn{2}{c}{ Fatores de saída } \\
\hline Família & 5 & Faculdade & 5 \\
\hline $\begin{array}{l}\text { Manutenção } \\
\text { cotidiana }\end{array}$ & 3 & $\begin{array}{l}\text { Falta radidade da } \\
\text { qualida } \\
\text { escola }\end{array}$ & 3 \\
\hline Casa & 2 & Emprego & 2 \\
\hline
\end{tabular}

Fonte: protocolo da pesquisa.

Ao colocarmos o foco na decisão entre ficar ou sair do campo, ou seja, nos fatores de permanência ou saída, conforme apresentamos neste trabalho, é necessário observar que muitos elementos são colocados na balança pelos/os jovens. Estar entre os seus, sua família, amigos/as, comunidade são fatores importantes, destacados pelos sujeitos da pesquisa. De modo inverso, a preocupação com a continuidade e a qualidade dos estudos que é entendido como caminho para a melhoria de vida e também das suas famílias, pode significar para eles não haver escolha, de maneira que o êxodo torna-se o único caminho.

Os processos de escolarização, no que diz respeito aos desafios enfrentados para acesso e permanência, bem como os aspectos de continuidade e qualidade, aparecem nas falas dos sujeitos como fatores de saída do campo de maneira similar ao que aparece em outros estudos como no de Leão e Antunes-Rocha (2015). Os autores afirmam que "em grande parte, esse movimento de saída é resultado das condições desfavoráveis de educação" (LEÃO; ANTUNES-ROCHA, 2015, p. 23).

A visão que os/as jovens manifestam sobre os processos de escolarização, a penosidade enfrentada para garantir o acesso e permanência, bem como, a preocupação com a qualidade dos processos formativos ficaram evidenciados nas falas dos sujeitos. Esse tema é discutido por Marinho (2016) que observa a problemática da ausência e má qualidade das escolas localizadas no campo, além da descontextualização do currículo em relação a realidade dos/as educandos/as. Para a autora, esses fatores contribuem para a expulsão de um grande número de jovens do campo em busca de melhores perspectivas.

C-A temática do projeto de vida foi fortemente evidenciada no presente estudo sendo que os sentidos estão agrupados em torno do desejo de se formar, incluindo a profissão que deseja seguir e o objetivo de melhorar a vida da sua família.

Entre os/as Jovens que desejam mudar para a cidade, medicina foi um curso que apareceu com destaque, um deles afirma que deseja: "[...] terminar o ensino médio, cursar uma universidade e me formar em medicina e ajudar meus pais e minhas 
DOI: $10.12957 /$ e-mosaicos.2020.44638

irmãs a realizarem seus sonhos também" (jovem Cristiano), enquanto outros não delimitaram e, ainda, desejam ter e/ou dirigir um negócio, enfatizando que gostariam de: "[...] estudar, aprender mais e mais e ter o conhecimento de dirigir uma empresa com bons negócios" (jovem Felipe).

Entre aqueles que pretendem permanecer no campo, aparece o objetivo de cursar Engenharia Florestal e Licenciatura em Educação Física, associado ao desejo de atuar na sua comunidade. Isto pode ser exemplificado por meio da afirmação do jovem João: "[...] desejo me formar em educação física e poder repassar meu conhecimento para a comunidade de onde eu fui".

Tabela 3 - Projeto de vida.

\begin{tabular}{l|l}
\hline \multicolumn{2}{c}{ Projeto de vida } \\
\hline Se formar & 20 \\
\hline Melhorar de vida & 8 \\
\hline $\begin{array}{l}\text { Ter uma profissão } \\
\text { Ser independente }\end{array}$ & 4 \\
\hline Outros & 6 \\
\hline
\end{tabular}

Fonte: protocolo da pesquisa.

Os dados levantados pela pesquisa em relação ao Projeto de vida dos/as Jovens da RESEX-CA corroboram com o que aponta Marinho (2016, p. 59-60) ao afirmar que: "[...] a permanência do jovem no campo se torna mais ameaçada principalmente quando o mesmo almeja um nível de ensino em descompasso com o ofertado na comunidade". As falas dos sujeitos evidenciam que o principal fator de saída do campo é a continuidade dos estudos. Isso reafirma que migrar nem sempre é uma escolha do/a jovem, mas uma condição imposta pela ausência de políticas públicas que possibilitem a permanência no campo.

Os resultados nos mostram as dificuldades de viver a condição juvenil no campo no contexto da Reserva Extrativista do Rio Cajari. Alcançar seus projetos implica, na maioria dos casos, em acessar maiores níveis de formação, o desejado curso superior, porém, sem abandonar sua identidade de jovem do campo. Essa problemática é apresentada no estudo realizado por Oliveira e Feliciano (2016). Os referidos autores afirmam que: "[...] a vontade de permanecer choca-se com a necessidade da saída do campo, [...] consolidando um movimento contraditório de busca, construção e desconstrução e resistência de jovens camponeses e camponesas" (OLIVEIRA; FELICIANO, 2016, p. 224). Esse movimento de idas e vindas, de resistência, dos/as 
DOI: $10.12957 / \mathrm{e}-\mathrm{mosaicos} .2020 .44638$

jovens do campo torna-se um desafio no sentido de construir seus projetos de vida, apesar das dificuldades enfrentadas ao longo do percurso.

Autores como Leão e Antunes-Rocha (2015), também, discutem essa temática, eles constataram que a educação, o trabalho e a questão fundiária são fatores decisivos que levam os/as jovens a tomar a decisão de sair do campo em busca de melhores condições de vida. Porém, em consonância com os resultados, levantados pelo presente estudo, os referidos autores entendem que o fato de os jovens buscarem a saída do campo como caminho não representa uma negação da vida no campo.

Uma reflexão que vem sendo construída em torno dos movimentos de idas e vindas de Jovens do campo é apresentada por Leão e Antunes-Rocha (2015). Para os autores, o fato de que muitos jovens buscam alternativas de saída, retorno, idas e vindas, expressa que não há uma negação da vida no campo.

Não obstante, nos desafios relatados pelo presente estudo, fica evidente que a decisão sobre permanecer (ou não) no campo não é uma decisão fácil. É um processo difícil, tenso e contraditório, onde, como afirma Marinho (2016), estão imbricados os laços cultivados pelos jovens com suas culturas e, ao mesmo tempo, a possibilidade de construir seus projetos de vida na cidade, permeados pela crença em algo melhor para si e para suas famílias que, em geral, está associada a estruturas sociais de educação, saúde, lazer, entre outros.

\section{CONSIDERAÇõES}

Os resultados da pesquisa ora apresentada apontam três temáticas que emergiram do agrupamento de informações dos/as entrevistados: os desafios para acesso ao ensino médio; a permanência no campo e os projetos de vida.

Os principais desafios enfrentados pelos/as Jovens da RESEX-CA para o acesso e a permanência na escola foram materializados em questões concretas, como: transporte, distância da escola e horário em que as atividades escolares são ofertadas, além da preocupação com a qualidade da educação. A superação dos desafios colocados pelos/as jovens passa pela efetivação de políticas públicas, como: transporte de qualidade, formação de professores com foco na educação do campo, gestão democrática nas escolas, entre outras. Essa construção é possível por meio de um processo de gestão qualificada com aplicação consciente dos recursos públicos.

Ao discutirmos sobre a permanência ou saída do campo, a família, os/as amigos/as e a comunidade são fatores importantes, destacados pelos sujeitos da pesquisa, enquanto, de modo inverso, a preocupação com a continuidade e a qualidade dos estudos, entendido por eles como possibilidade para a melhoria de vida e, também, para suas famílias, colocam a cidade como único caminho possível.

A educação que está ao alcance dos/as jovens em seus territórios não condiz com os desejos e projetos de vida que eles/as têm, ou seja, que os possibilite acessar 
DOI: $10.12957 / \mathrm{e}-\mathrm{mosaicos} .2020 .44638$

o ensino superior. Acessar maiores níveis de ensino atualmente implica no deslocamento para as cidades. Essa realidade que impede o acesso ao ensino superior pode ser transformada com a construção de propostas adequadas à realidade do campo por meio dos processos de alternância pedagógica, como exemplo, a licenciatura em educação do campo e os cursos ofertados pela Programa Nacional de Educação na Reforma Agrária (PRONERA).

De um modo geral, os/as jovens vivem seus projetos de vida atravessados pela dúvida entre a manutenção dos laços e vínculos construídos nas suas famílias e comunidades e a busca pelo conhecimento, a profissionalização e a desejada melhoria nas condições de vida que, no contexto vivenciado, atualmente passa pelo êxodo. Nesse sentido, ficar ou sair do campo não é necessariamente questão de escolha e/ou projeto de vida, é uma necessidade no sentido do acesso a direitos básicos como educação, trabalho, mobilidade, entre outros.

Por fim, o estudo sinaliza que as juventudes que vivem no campo ainda sofrem desenraizamento de suas origens, famílias e culturas, uma vez que as oportunidades se encontram centralizadas na cidade. Esse cenário faz com que um contingente significativo de jovens permaneça no campo por não ter condições financeiras e/ou infraestrutura que o mantenha na cidade para a continuidade de seus estudos. Desse modo, seus projetos de vida ficam restritos aos sonhos e a esperança de que um dia possa transformar em realidade a vida com qualidade no campo, para que possa exercer o direito de escolher viver nos seus territórios e não ser empurrado para os centros urbanos em busca de melhores oportunidades.

\section{REFERÊNCIAS}

ALVES, Maria Zenaide. Crescendo "longe demais das capitais": um olhar sobre a Juventude de um município rural mineiro. In: LEÃO, Geraldo; ANTUNES-ROCHA, Maria Isabel (org.). Juventudes do campo. Belo Horizonte: Editora Autêntica, 2015. p. 87-104. (Coleção Caminhos da Educação).

BRASIL. Lei no 12.061, de 27 de outubro de 2009. Altera o inciso II do art. 40 e o inciso VI do art. 10 da Lei no 9.394, de 20 de dezembro de 1996, para assegurar o acesso de todos os interessados ao ensino médio público. Brasília, DF, Presidência da República. Disponível em: http://www.planalto.gov.br/ccivil_03/_Ato20072010/2009/Lei/L12061.htm. Acesso em: 15 set. 2019.

BRASIL. Lei no 0949, de 23 de dezembro de 2005. Dispõe sobre normas de funcionamento do Sistema Estadual de Educação, reestrutura o Grupo Magistério do Quadro de Pessoal do Governo do Estado do Amapá e organiza o Plano de Cargos, Carreiras e Salários dos profissionais da educação básica do Poder Executivo Estadual. Brasília, DF, Presidência da República. Disponível em: http://www4.planalto.gov.br/legislacao/. Acesso em: 15 set. 2019. 
DOI: $10.12957 /$ e-mosaicos.2020.44638

BRAUN, Virginia; CLARKE, Victoria. Using thematic analisys in psychology. Tradução de Luiz Fernando Mackedanz. Qualitative Research in Psychology, São Paulo, v. 3, n. 2, p. 77-101, 2006. Disponível em: http://eprints.uwe.ac.uk/11735/. Acesso em: 15 set. 2019.

CAMPOS, Névio de; RODRIGUES, Marli de Fátima; VITKOWSKI, José Rogério. Escolarização, cidadania e juventude em São João do Triunfo - PR, 2012. Disponível em: http://www.revistas2.uepg.br/index.php/emancipacao/article/view/1234/3129. Acesso em: 15 set. 2019.

DURAND, Olga Celestina da Silva; ALVES, Suzy de Castro. Juventude do campo na busca da escolarização/qualificação: uma experiência em Santa Catarina. In: LEÃO, Geraldo; ANTUNES-ROCHA, Maria Isabel (org.). Juventudes do campo. Belo Horizonte: Editora Autêntica, 2015. p. 69-86. (Coleção Caminhos da Educação).

GALINDO, Éryka. Sou jovem do campo: caminhos de construção da identidade juvenil no sindicalismo rural. In: LEÃO, Geraldo; ANTUNES-ROCHA, Maria Isabel (org.). Juventudes do campo. Belo Horizonte: Editora Autêntica, 2015. p. 107-124. (Coleção Caminhos da Educação).

GIL, Antônio Carlos. Métodos e técnicas em pesquisa social. 6. ed. São Paulo: Atlas, 2008.

LEÃO, Geraldo; ANTUNES-ROCHA, Maria Isabel. Juventudes no/do campo: questões para um debate. In: LEÃO, Geraldo; ANTUNES-ROCHA, Maria Isabel (org.).

Juventudes do campo. Belo Horizonte: Editora Autêntica, 2015. p. 17-27. (Coleção Caminhos da Educação).

LEÃO, Geraldo; DAYRELL, Juarez Tarcísio; BATISTA DOS REIS, Juliana. Juventude, Projetos de Vida e Ensino Médio. Educação \& Sociedade [online], Campinas, v. 32, n. 117, p. 1067-1084, out./dez.2011. Disponível em:

http://www.scielo.br/scielo.php?script=sci arttext\&pid=S0101-73302011000400010. Acesso em: 15 set. 2019.

MARINHO, Dalcione Lima. Rompendo as cercas e construindo saberes: a juventude na construção da educação profissional do campo no sudeste do Pará. Recife: Imprima, 2016.

NASCIMENTO, Ivany Pinto. Um diálogo com o campo das Representações Sociais. In: ORNELLAS, Maria de Lourdes Soares (org.). Representações sociais e educação: letras imagéticas III. Salvador: EDUFBA, 2015. p. 45-68.

NASCIMENTO, Ivany Pinto. Educação e Projeto de vida de adolescentes do ensino médio. EccoS Revista Científica - Universidade Nove de Julho, São Paulo, n. 31, p. 83-100, maio-ago. 2013. 
DOI: $10.12957 / \mathrm{e}-\mathrm{mosaicos} .2020 .44638$

OLIVEIRA, Luciano Benini de; FELICIANO, Carlos Alberto. Entre o campo e a cidade: reflexões sobre o espaço da juventude camponesa. Revista Pegada [online], São Paulo, v. 17, n.2, p. 208-225, dez. 2016. Disponível em: http://revista.fct.unesp.br/index.php/pegada/article/viewFile/4678/3588. Acesso em: 15 set. 2019.

PENATIERI, Gisele Rogéria. Sentidos e reflexos da escolarização na atualidade na visão de jovens alunos do ensino médio, 2012. Disponível em: https://document.onl/documents/sentidos-e-reflexos-da-escolarizacao-narepresentacoes-de-jovens-sobre-suas.html. Acesso em: 15 set. 2019.

Recebido em 19 de agosto de 2019 Aceito em 11 de outubro de 2019 com o direito de primeira publicação cedido à e-Mosaicos.

Os artigos publicados são de acesso público, de uso gratuito, com atribuição de autoria obrigatória, para aplicações de finalidade educacional e não-comercial, de acordo com o modelo de licenciamento Creative Commons adotado pela revista. 